\title{
Impact of neoadjuvant therapy in downstaging of lower rectal adenocarcinoma and the role of pelvic magnetic resonance in staging
}

\author{
Impacto da terapia neoadjuvante na diminuição do estádio no adenocarcinoma de \\ reto baixo: papel da ressonância magnética da pelve na determinação do estádio
}

Karina Dagre Magri ; Fang Chia Bin' TCBC-SP1; Fernanda Bellotti Formiga ${ }^{1}$; Thiago da Silveira Manzione, ACBC-SP2; Caroline Merci Caliari de Neves Gomes'; Paulo de Azeredo Passos Candelári, TCBC-SP2; Jorge Alberto Ortiz,TCBC-SP2; Wilmar Artur Klug ${ }^{1}$; José Mandia Neto'; Peretz Capelhuchnik, TCBC-SP1.

\begin{abstract}
A B S TR A C T
Objective: to evaluate the effect of neoadjuvant therapy on the stage (TNM) of patients with rectal adenocarcinoma and validate the use of MRI as a method of determining locoregional stage. Methods: we conducted a retrospective study of 157 patients with lower rectum adenocarcinoma, whom we divided into two groups: Group 1, 81 patients (52\%) who had undergone surgical treatment initially, with the purpose to analyze the accuracy of locoregional staging by pelvic magnetic resonance imaging throug the comparison of radiological findings with pathological ones; Group 2, 76 patients (48\%), who had been submitted to neoadjuvant therapy (chemotherapy and radiation) prior to definitive surgical treatment, so as to evaluate its effects on the stage by comparing clinical and radiological findings with pathology. Results: In group 1, the accuracy of determining tumor depth (T) and lymph node involvement (N) was $91.4 \%$ and $82.7 \%$, respectively. In group 2, neoadjuvant therapy decreased the T stage, $\mathrm{N}$ stage and TNM stage in $51.3 \%, 21 \%$ and $48.4 \%$ of cases, respectively. Conclusion: neoadjuvant therapy in patients with rectal adenocarcinoma is effective in decreasing disease stage, and pelvic magnetic resonance imaging is effective for locoregional staging.
\end{abstract}

Keywords: Adenocarcinoma. Rectal Neoplasms. Neoadjuvant Therapy. Magnetic Resonance Imaging. Neoplasm Staging.

\section{INTRODUCTION}

Surgical resection of rectal cancer is still the only $S_{\text {possibility of cure and is still regarded as the main }}$ form of treatment for many authors ${ }^{1.2}$. The evolution of the surgical technique, except for the access routes, reached its peak after finding that the total mesorectal excision and resection of the circumferential margin significantly decrease local recurrence ${ }^{3}$.

In the 90s, it has become consensus that the treatment of adenocarcinoma of the rectum stages II and III would require, in addition to the operation, complementary chemotherapy and radiotherapy, after the discovery of their beneficial effects in reducing disease recurrence and increasing long-term survival rates 4 . Despite this evolution, the treatment of rectal cancer remains challenging, since long-term survival has not evolved consistently $y^{5}$. Eight large clinical series were published that analyzed neoadjuvant therapy for rectal cancer. All these studies demonstrated a superiority of this therapeutic modality when compared with surgery performed in an exclusive manner, as well as in relation to the adjuvant therapy².

Among the benefits of neoadjuvant radiotherapy and chemotherapy, there are: increased preoperative radiosensitivity of tissues due to the absence of surgical fibrosis, lower exposure of the small intestine to radiation, lower systemic toxicity, and decrease in lesions' size, which increase resectability and the sphincter preservation rate $^{6}$. As disadvantages we have: the potential deficiency in the accurate determination of pathologic stage, which may result in failure of the postoperative planning, the postponement of definitive surgical treatment, and possible increase in morbidity and operative mortality?. Currently, patients with resectable lower

1 - Faculdade de Ciências Médicas da Santa Casa de São Paulo, São Paulo, SP, Brasil; 2 - Irmandade da Santa Casa de Misericórdia de São Paulo, São Paulo, SP, Brasil. 
rectal cancer in stages II and III should be submitted to neoadjuvant therapy provided they do not have medical contraindications ${ }^{8}$.

Thus, the precise determination of the stage (TNM) is essential for the treatment to be well indicated $^{2}$. As a general rule, Computerized Tomography of the chest and abdomen is the choice for the detection of metastatic disease (M), and the pelvic magnetic resonance imaging (MRI) or the transrectal ultrasonography are better to determine the locoregional stage ( $\mathrm{T}$ and $\mathrm{N})^{9}$. Conceptually, the ultrasound exam is superior in the analysis of smaller and more superficial tumors when compared with MRI, which has better accuracy in larger tumors that extend beyond the circumferential margin ${ }^{10,11}$.

The objectives of this study were to evaluate the effect of neoadjuvant therapy on the stage of patients with low rectal adenocarcinoma and to validate the use of MRI as a method of determining locoregional stage.

\section{METHODS}

We held a retrospective analysis of 157 medical records of patients diagnosed with lower rectal adenocarcinoma during the period from February 2005 to October 2012. This study was approved by the Ethics in Research Committee of the Irmandade da Santa Casa de Misericórdia de São Paulo, under number 109,338.

We divided patients into two groups according to the initial therapeutic approach: Group 1, patients initially referred to surgical treatment, on an elective basis, after preoperative staging; Group 2, patients who, after having their stage determined, were referred to neoadjuvant therapy prior to definitive surgical treatment. The operation in these cases was performed eight weeks after completion of the neoadjuvant therapy, without further staging by imaging methods.

We performed preoperative staging by physical, proctologic and radiological examination, CT scan of the chest and upper abdomen to assess systemic disease (distant metastases) and pelvic MRI to evaluate locoregional involvement. The final stage was determined by the pathological examination of surgical specimens, associated with pre- and intraoperative findings. For the stage description, we adopted the system described by the American Joint Committee on Cancer ${ }^{12}$.

All imaging tests in this series were performed at the Radiology Service of the Irmandade da Santa Casa de Misericórdia de São Paulo, using MRI machines models Philips Intera 1.0T or Philips Achieva 1.5T SE.

Depending on tumor location and intraoperative conditions, the performed procedures were abdominal rectosigmoidectomy or rectal amputation with total mesorectal excision.

The chemotherapy regimen employed in patients undergoing neoadjuvant therapy was 5-fluorouracil at a dose of $380 \mathrm{mg} / \mathrm{m}^{2}$ and Leucovorin $20 \mathrm{mg} /$ $\mathrm{m}^{2}$ for five consecutive days (D1 to D5) concurrent with the first and fifth week of radiation therapy. The body surface area was obtained from the formula: Weight $(\mathrm{kg})^{0.425} \times$ Height $(\mathrm{cm})^{0.725} \times 71.84 / 10.000$.

Radiotherapy consisted of 28 sessions in five weeks and three days of 180cGy per session, total 5040 cGy.

We excluded from the study patients with history of colorectal cancer surgery, those operated in the emergency department or undergoing palliative surgery, and those who abandoned treatment.

We analyzed the variables gender, age at diagnosis, depth of tumor invasion in the rectal wall $(T)$, lymph node involvement $(N)$, presence of metastases (M), preoperative and final stages (TNM).

For the statistical analysis of the results we applied the Wilcoxon and McNemar tests to verify possible differences between variables $T, N, M$ and the stage of both groups. We did not compare Groups 1 and 2. We used a spreadsheet software for data organization and the IBM SPSS (Statistical Package for Social Sciences), version 21.0, to obtain the results.

\section{RESULTS}

Of the 157 patients, 81 (52\%) correspond to Group 1, in which the surgery was performed first, 
and 76 (48\%) to Group 2, in which the neoadjuvant therapy was performed before the operation.

The average age of Group 1 patients was 58.27 years \pm 13.15 , while in Group 2 it was 59.96 years \pm 11.81 .

In Group 1, 33 (41\%) individuals were women, with a mean age of 58.63 years \pm 13.44 , and 48 men were (59\%), mean age 58.02 years \pm 13.09 .

As for Group 2 patients, 37 (49\%) were women, with a mean age of 59.56 years \pm 12.62 , and 39 men (51\%), mean age of 60.33 years \pm 11.15

\section{Group 1 Results}

The analysis of radiological and pathological correlation of the T variable detected no statistically significant variation, with accuracy of $91 \%$ (Figure 1).

The analysis of radiological and pathological correlation of the $\mathrm{N}$ variable detected no statistically significant variation, with accuracy of $83 \%$ (Figure 2).

The variable $\mathrm{M}$ remained constant, both pre and postoperatively. The correlation between clinical stage and the final stage showed agreement in $84 \%$ of cases. In $11 \%$ of cases, the stage was initially underestimated, and in 4\%, overestimated. There was one case in which the lesion was not detected (Figure 3).

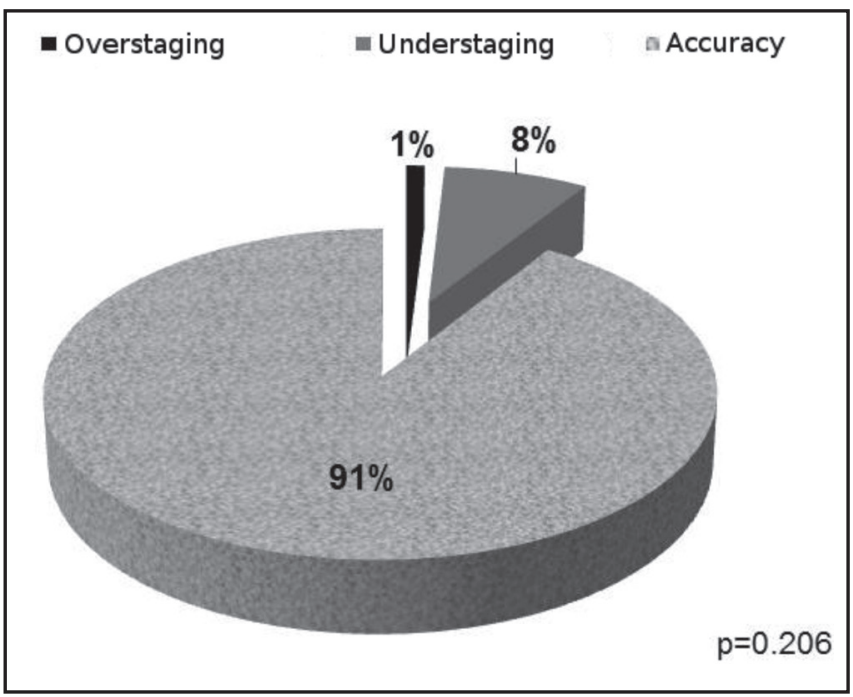

Figure 1: Radiological and pathological correlation of changes in variable T in the 81 Group 1 patients. Source: ISCMSP, 2013.

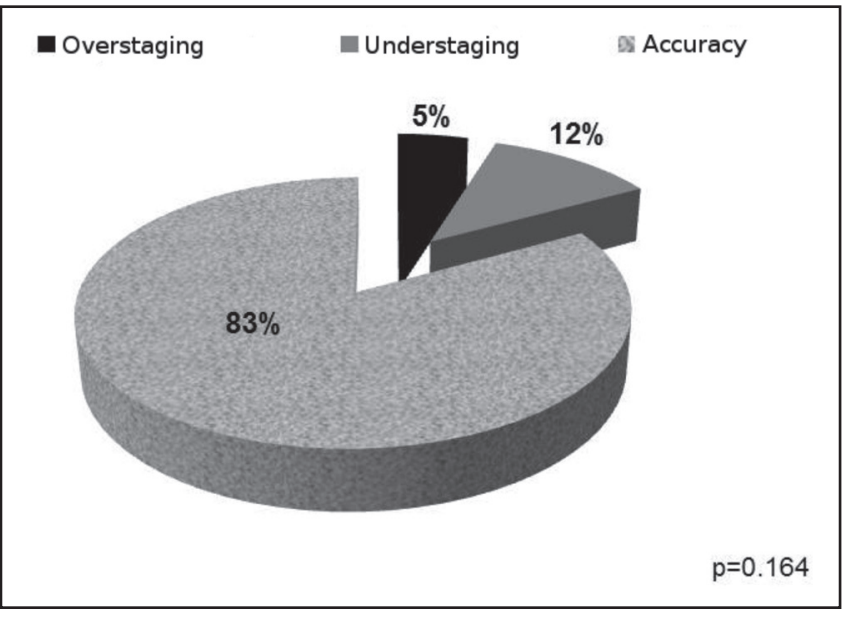

Figure 2: Radiological and pathological correlation of changes in variable $N$ in the 81 Group 1 patients. Source: ISCMSP, 2013.

\section{Group 2 Results}

The analysis of the effect of neoadjuvant therapy on the variable $T$ showed that there was regression in $51 \%$ of cases, and the pathological response (TO) occurred in $17 \%$ of cases (Table 1).

The analysis of the effect of neoadjuvant therapy on the variable $\mathrm{N}$ showed regression in $21 \%$ of cases (Table 2).

The analysis of the effect of neoadjuvant therapy on the variable $\mathrm{M}$ demonstrated that there was an increase in the occurrence of distant metastases of around $7 \%$, with no statistical significance.

The analysis of the effect of neoadjuvant therapy on stage displayed a regression of $48.5 \%$

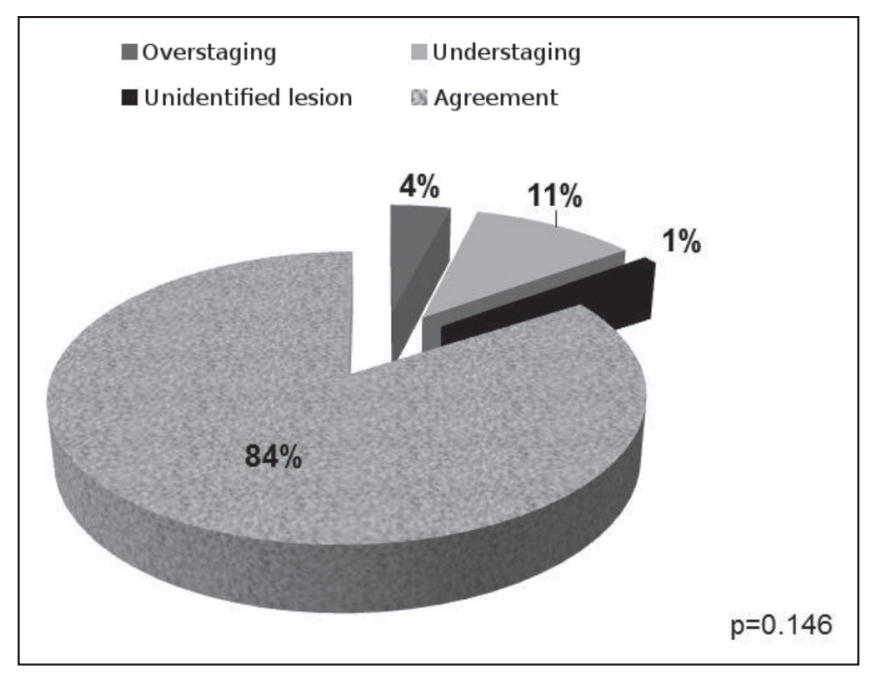

Figure 3: Correlation between clinical and final stages in the 81 Group 1 patients. Source: ISCMSP, 2013. 
Table 1: Variable T: comparison between radiological determination and histopathology in Group 2.

\begin{tabular}{|c|c|c|c|c|c|c|c|c|}
\hline \multirow{2}{*}{ Group } & \multirow{2}{*}{ cT } & \multicolumn{5}{|c|}{ ypT } & \multirow{2}{*}{ Total } & \multirow{2}{*}{ Sig. (p) } \\
\hline & & 0 & 1 & 2 & 3 & 4 & & \\
\hline \multirow{10}{*}{ Neoadjuvancy } & \multirow{2}{*}{1} & 1 & 0 & 0 & 1 & 0 & 2 & \multirow{10}{*}{$<0,001$} \\
\hline & & $1.3 \%$ & $0 \%$ & $0 \%$ & $1.3 \%$ & $0 \%$ & $2.6 \%$ & \\
\hline & \multirow{2}{*}{2} & 2 & 1 & 4 & 6 & 0 & 13 & \\
\hline & & $2.6 \%$ & $1.3 \%$ & $5.3 \%$ & $7.9 \%$ & $0 \%$ & $17.1 \%$ & \\
\hline & \multirow{2}{*}{3} & 8 & 1 & 13 & 21 & 1 & 44 & \\
\hline & & $10.5 \%$ & $1.3 \%$ & $17.1 \%$ & $27.6 \%$ & $1.3 \%$ & $57.9 \%$ & \\
\hline & \multirow{2}{*}{4} & 2 & 0 & 1 & 10 & 4 & 17 & \\
\hline & & $2.6 \%$ & $0 \%$ & $1.3 \%$ & $13.2 \%$ & $5.3 \%$ & $22.4 \%$ & \\
\hline & \multirow{2}{*}{ Total } & 13 & 2 & 18 & 38 & 5 & 76 & \\
\hline & & $17.1 \%$ & $2.6 \%$ & $23.7 \%$ & $5 \%$ & $6.6 \%$ & $100 \%$ & \\
\hline
\end{tabular}

Source: ISCMSP, 2013. Teste dos Postos Sinalizados de Wilcoxon.

and a $20 \%$ increase. We observed a complete pathological response rate of $14.5 \%$, which corresponds to 11 cases (Table 3). The exclusion of stages I and IV shows that stage regression occurs in $56 \%$ of cases, with complete pathological response in $16 \%$.

\section{DISCUSSION}

The first large prospective randomized study that demonstrated the effectiveness of neoadjuvant chemotherapy and radiotherapy came from Germany in 2004. It randomized 823 patients to receive chemotherapy and radiation preoperatively (421 cases) and postoperatively (402 cases). The authors found that the incidence of local recurrence at five years was $6 \%$ versus $13 \%$, respectively. There was no significant increase in survival in five years between the groups ${ }^{13}$.

Although the optimal regimen of neoadjuvant treatment is not yet well defined, there is no doubt of its effectiveness, especially in the control of local re- currence, and hence the increase in disease-free interval $^{2}$. There is a polarization between the European and US institutions. In European publications, preference is mainly for short cycles of neoadjuvant radiotherapy, because they have lower morbidity. In American studies, similar to what was done in this study, preference is given to cycles with longer duration, arguing that the reduction of tumor size is more efficient.

The intent of this study was to analyze, in a stratified manner, the effects of neoadjuvant therapy on the stage (TNM) and on their individual variables in Group 2 patients. These variables were determined in two specific moments: preoperatively, with the aid of pelvic MRI (for the determination of locoregional stage $-\mathrm{T}$ and $\mathrm{N}$ ) and chest and abdomen $\mathrm{CT}$ scan (for detecting distant metastases - M); and in the postoperative period, through histopathology data.

One might question maintaining the $M$ variable in this study, since neoadjuvant therapy has essentially locoregional effects. However, its analysis

Table 2: Variable N: comparison between radiological determination and histopathology in Group 2.

\begin{tabular}{|c|c|c|c|c|c|c|}
\hline \multirow{2}{*}{ Group } & \multirow{2}{*}{$\mathrm{CN}$} & \multicolumn{3}{|c|}{ ypN } & \multirow{2}{*}{ Total } & \multirow{2}{*}{ Sig. (p) } \\
\hline & & 0 & 1 & 2 & & \\
\hline \multirow{8}{*}{ Neoadjuvancy } & \multirow{2}{*}{0} & 42 & 2 & 5 & 49 & \multirow{8}{*}{0,036} \\
\hline & & $55.3 \%$ & $2.6 \%$ & $6.6 \%$ & $64.5 \%$ & \\
\hline & \multirow{2}{*}{1} & 11 & 7 & 1 & 19 & \\
\hline & & $14.5 \%$ & $9.2 \%$ & $1.3 \%$ & $25 \%$ & \\
\hline & \multirow{2}{*}{2} & 2 & 3 & 3 & 8 & \\
\hline & & $2.6 \%$ & $3.9 \%$ & $3.9 \%$ & $10.5 \%$ & \\
\hline & \multirow{2}{*}{ Total } & 55 & 12 & 9 & 76 & \\
\hline & & $72.4 \%$ & $15.8 \%$ & $11.8 \%$ & $100 \%$ & \\
\hline
\end{tabular}

Source: ISCMSP, 2013. Teste de McNemar. 
Table 3. Comparison between clinical and final stages in Group 2.

\begin{tabular}{|c|c|c|c|c|c|c|c|c|c|c|c|}
\hline \multirow{2}{*}{ Group } & \multirow{2}{*}{ Clinical stage } & \multicolumn{8}{|c|}{ Pathological stage } & \multirow{2}{*}{ Total } & \multirow{2}{*}{ Sig. (p) } \\
\hline & & 0 & I & $\| \mathrm{A}$ & IIB & IIIA & IIIB & IIIC & IV & & \\
\hline \multirow{16}{*}{ Neoadjuvancy } & \multirow{2}{*}{ I } & 1 & 3 & 5 & 0 & 1 & 0 & 0 & 0 & 10 & \multirow{16}{*}{0.012} \\
\hline & & $1.3 \%$ & $3.9 \%$ & $6.6 \%$ & $0 \%$ & $1.3 \%$ & $0 \%$ & $0 \%$ & $0 \%$ & $13.2 \%$ & \\
\hline & \multirow{2}{*}{$\| A$} & 6 & 8 & 10 & 1 & 0 & 1 & 2 & 2 & 30 & \\
\hline & & $7.9 \%$ & $10.5 \%$ & $13.2 \%$ & $1.3 \%$ & $0 \%$ & $1.3 \%$ & $2.6 \%$ & $2.6 \%$ & $39.5 \%$ & \\
\hline & \multirow{2}{*}{ IIB } & 2 & 1 & 3 & 1 & 0 & 0 & 0 & 1 & 8 & \\
\hline & & $2.6 \%$ & $1.3 \%$ & $3.9 \%$ & $1.3 \%$ & $0 \%$ & $0 \%$ & $0 \%$ & $1.3 \%$ & $10.5 \%$ & \\
\hline & \multirow{2}{*}{ IIIA } & 0 & 2 & 1 & 0 & 1 & 0 & 0 & 0 & 4 & \\
\hline & & $0 \%$ & $2.6 \%$ & $1.3 \%$ & $0 \%$ & $1.3 \%$ & $0 \%$ & $0 \%$ & $0 \%$ & $5.3 \%$ & \\
\hline & \multirow{2}{*}{ IIIB } & 1 & 4 & 3 & 0 & 1 & 5 & 0 & 1 & 15 & \\
\hline & & $1.3 \%$ & $5.3 \%$ & $3.9 \%$ & $0 \%$ & $1.3 \%$ & $6.6 \%$ & $0 \%$ & $1.3 \%$ & $19.7 \%$ & \\
\hline & \multirow{2}{*}{$\| \mathrm{IIC}$} & 1 & 0 & 0 & 1 & 0 & 2 & 2 & 1 & 7 & \\
\hline & & $1.30 \%$ & $0 \%$ & $0 \%$ & $1.3 \%$ & $0 \%$ & $2.6 \%$ & $2.6 \%$ & $1.3 \%$ & $9.2 \%$ & \\
\hline & \multirow{2}{*}{ IV } & 0 & 0 & 0 & 0 & 0 & 0 & 0 & 2 & 2 & \\
\hline & & $0 \%$ & $0 \%$ & $0 \%$ & $0 \%$ & $0 \%$ & $0 \%$ & $0 \%$ & $2.6 \%$ & $2.6 \%$ & \\
\hline & \multirow{2}{*}{ Total } & 11 & 18 & 22 & 3 & 3 & 8 & 4 & 7 & 76 & \\
\hline & & $14.5 \%$ & $23.7 \%$ & $28.9 \%$ & $3.9 \%$ & $3.9 \%$ & $10.5 \%$ & $5.3 \%$ & $9.2 \%$ & $100 \%$ & \\
\hline
\end{tabular}

Source: ISCMSP, 2013. Teste dos Postos Sinalizados de Wilcoxon.

is mainly for the correct determination of the stage, which depends critically on the three variables ( $T, N$ and $\mathrm{M}$ ). Furthermore, despite its systemic effects are still scarcely mentioned, some authors demonstrated that neoadjuvant chemotherapy may start the early systemic treatment of metastases, and be used as a marker of tumor response, which may enhance subsequent treatment ${ }^{14}$.

Group 1 corresponds to a period in which neoadjuvant therapy was not yet established in the service. From the end of 2007 on, patients who presented in clinical stage II or III (T3 NO MO or $\mathrm{T} 1,2,3 \mathrm{N1}, 2 \mathrm{M0}$ ) have been submitted to neoadjuvant therapy.

The reason for analyzing Group 1 patients, of different treatment, was primarily to assess the quality in determining the clinical stage in our service, as it was the same throughout the sample of this series, both in Groups 1 and 2. Thus, the bias of overstaging or understaging, that MRI may potentially present, was eliminated. In Group 1, there was a significant correlation between the clinical and pathological stages, which occurred in $91 \%$ of cases for the variable $\mathrm{T}$ and $83 \%$ for the variable $\mathrm{N}$.

For many authors, pelvic MRI is considered the most suitable technique for determining locore- gional stage, due to its high sensitivity and specificity in the analysis of structures adjacent to the rectum, including the mesorretal fascia ${ }^{15}$. Likewise, it is the only available technique for the proper assessment of the circumferential margin (CRM), currently considered one of the most important prognostic factors of local recurrence. In a recent American publication, the authors concluded that CRM $\leq 1 \mathrm{~mm}$ is an independent risk factor for local recurrence, equivalent to surgical safety margin; CRM $\leq 2 \mathrm{~mm}$, on its turn, is associated with the occurrence of distant metastases, regardless of tumor depth $(\mathrm{T})$ and lymph node involvement $(\mathrm{N})^{16}$.

According to Mortensen et al. ${ }^{17}$, the MRI accuracy in determining tumor depth varies with the level of rectum wall involvement, as follows: T1 lesions - 75\%; T2 - 54\%; T3 - 87\%; and T4 - 86\%. As for lymph node involvement, MRI's accuracy is up to $85 \%{ }^{15}$.

A meta-analysis published in 1997, involving 26 publications with 1,976 patients, found that endorectal ultrasound has an accuracy of $88 \%$ in stage determination ${ }^{17}$. Among the disadvantages related to ultrasound, we can mention that is an operator-dependent examination; It has low sensitivity in distinguishing inflammatory thickening from trans- 
mural tumor extension itself; bulky and stenotic lesions are technically difficult to assess; its application in patients undergoing neoadjuvant therapy is still being determined, but the initial data are favorable to pelvic MRI ${ }^{9}$.

MRI is indeed an excellent method for assessing tumor invasion in the rectal wall, but the same can not be said with respect to lymph node involvement, since the literature data are not so encouraging. It has increasingly been given importance to the morphological characteristics of perirectal lymph nodes, such as their heterogeneity and jagged edges, which are more predictive than their dimensions ${ }^{18}$. We should point out that $18 \%$ of lymph node metastases occur in lymph nodes smaller than $5 \mathrm{~mm}^{19}$.

This topic becomes even more important regaring the new stage determination after the neoadjuvant therapy. The literature reveals that the current diagnostic methods, such as positron emission tomography ${ }^{20}$ and high-resolution MR2 ${ }^{21}$, are still inconsistent in the evaluation of residual, clinically undetectable disease. In this series, we did not have a new stage determination because we believe that the ideal cancer treatment should be based on the initially set clinical stage, so that there would be no change in surgical planning. Nevertheless, we found $14.5 \%$ of complete pathological response, which makes us think about new treatment perspectives. Another very relevant aspect is the great complexity of performing MRI in the service where the study was conducted, due to high demand and high cost.

There is a lot of controversy in the literature regarding the ideal time interval to perform the operation. Those defending shorter time intervals suggest that the operative difficulties are smaller due to lower incidence of adhesions and fibrosis arising from the pelvic radiation, allowing the realization of a more radical procedure; they also argue that the risk of disease dissemination would be lower. Those defending longer time intervals believe that the incidence of complete pathological response is higher. Tulchinsky et al. ${ }^{22}$ found complete pathological response rates of $35 \%$ in patients operated after seven weeks, compared with $17 \%$ in those operated before this pe- riod. In our sample, the time interval between the completion of neoadjuvant therapy and surgery was eight weeks, and the complete pathological response rate was similar to the study of Rödel et al. ${ }^{23}$, which reached $17 \%$. However, stage regression in our study was $48.5 \%$, an index similar to the one published by Kuriu et al. ${ }^{24}$, of $40 \%$.

This relatively below average index, with regards to the complete pathological response we obtained in our study, can be attributed to some existing naming discrepancies in the literature to describe the tumor behavior to neoadjuvant therapy. It is clear that often used terms, such as "downstaging", "downsizing", "tumor regression", may be wrongly employed. Isolated alterations in variables T, $\mathrm{N}$ or $\mathrm{M}$ may not necessarily be interpreted as stage reduction. Stage regression shall be determined by the combined analysis of variables (TNM) ${ }^{2}$. WE should note that, by definition, the concept of complete pathological response should be translated as TONOMO, ie no identification of tumor in the surgical specimen. The concept of complete clinical response, on its turn, is the absence of clinically detectable residual disease after neoadjuvant treatment ${ }^{25}$.

We observed that neoadjuvant therapy regressed $\mathrm{T}$ stage in $51 \%$ of cases, and for variable $\mathrm{N}$ this index amounted to $21 \%$. Despite this difference, both were significant from a statistical point of view. The relatively low response of $\mathrm{N}$ in relation to $\mathrm{T}$ is the one responsible for the great discussion generated around the therapeutic modality of expectant management in the face of complete clinical response $\mathrm{e}^{26,27}$.

There is no doubt that neoadjuvant therapy brings concrete benefits for patients with rectal adenocarcinoma, such as increased incidence of operations with sphincter preservation ${ }^{28}$, although many questions are still far from being answered. Among them, how to identify non-responders? Despite the lack of statistical significance in our series, we found stage progression in $20 \%$ of cases. The importance of early identification of patients who will not respond to this treatment modality would probably prevent disease progression, since the time relapsed between the end of therapy and surgery is not negligible. 
With the evolution of diagnostic imaging methods and advances in molecular biology, new neoadjuvant therapy protocols will emerge in the near future to guide more individualized treatment modes, reducing adverse effects and not delaying surgical treatment, which is undoubtedly still the only curative therapy.
In conclusion, in patients with rectal adenocarcinoma neoadjuvant therapy and magnetic resonance imaging of the pelvis are both effective, the former in stage reduction, and the latter as a method of determining locoregional stage.

\title{
R E S U M O
}

\begin{abstract}
Objetivo: avaliar o efeito da terapia neoadjuvante, nos pacientes portadores de adenocarcinoma de reto, sobre o estádio (TNM) e validar o emprego da ressonância magnética como método de determinação do estádio locorregional. Métodos: estudo retrospectivo de 157 pacientes com diagnóstico de adenocarcinoma de reto baixo, que foram divididos em dois grupos: Grupo 1, 81 pacientes (52\%), submetidos ao tratamento cirúrgico de princípio, cuja finalidade foi analisar a acurácia da determinação do estádio locorregional pela ressonância magnética da pelve, através da comparação entre os achados radiológicos e os achados anatomopatológicos; Grupo 2, 76 pacientes (48\%), encaminhados à terapia neoadjuvante (quimioterapia e radioterapia), antes do tratamento cirúrgico definitivo, com o intuito de avaliar seus efeitos sobre o estádio, através da comparação dos achados clínico-radiológicos com os anatomopatológicos. Resultados: no grupo 1, a acurácia da determinação da profundidade da lesão (T) e do comprometimento linfonodal (N), foram de 91,4\% e 82,7\%, respectivamente. No grupo 2, a terapia neoadjuvante diminuiu o estádio T, estádio $N$ e o estádio TNM em $51,3 \%, 21 \%$ e 48,4\% dos casos, respectivamente. Conclusão: a terapia neoadjuvante nos pacientes com adenocarcinoma de reto é efetiva na diminuição do estádio e a ressonância magnética da pelve é eficaz na determinação do estádio locorregional.
\end{abstract}

Descritores: Adenocarcinoma. Neoplasias Retais. Terapia Neoadjuvante. Imagem por Ressonância Magnética. Estadiamento de Neoplasias.

\section{REFERENCES}

1. Lange MM, Martz JE, Ramdeen B, Brooks V, Boachie-Adjei K, van de Velde CJ, et al. Longterm results of rectal cancer surgery with a systematical operative approach. Ann Surg Oncol. 2013;20(6):1806-15.

2. Kosinski L, Habr-Gama A, Ludwig K, Perez R. Shifting concepts in rectal cancer management: a review of contemporary primary rectal cancer treatment strategies. CA Cancer J Clin. 2012;62(3):173-202.

3. Heald RJ, Ryall RD. Recurrence and survival after total mesorectal excision for rectal cancer. Lancet. 1986;1(8496):1479-82.

4. NIH consensus conference. Adjuvant therapy for patients with colon and rectal cancer. JAMA. 1990;264(11):1444-50.

5. O'Connell JB, Maggard MA, Ko CY. Colon cancer survival rates with the new American Joint Committee on Cancer sixth edition staging. J Natl Cancer Inst. 2004;96(19):1420-5.

6. Willett CG, Warland G, Coen J, Shellito PC,
Compton CC. Rectal cancer: the influence of tumor proliferation on response to preoperative irradiation. Int J Radiat Oncol Biol Phys. 1995;32(1):57-61.

7. Holm T, Singnomklao T, Rutqvist LE, Cedermark B. Adjuvant preoperative radiotherapy in patients with rectal carcinoma. Adverse effects during long term follow-up of two randomized trials. Cancer. 1996;78(5):968-76.

8. National Comprehensive Cancer Network. NCCN Practice Guidelines for Colon and Rectal Cancer. NCCN Version 2010. Washington, DC; 2010.

9. Samee A, Selvasekar CR. Current trends in staging rectal cancer. World J Gastroenterol. 2011;17(7):828-34.

10. Ceelen WP. Progress in rectal cancer treatment. ISRN Gastroenterol. 2012;2012:648183.

11. Marohn MRI. Endorectal ultrasound. Postgradute course syllabus. SAGES; 1997:126-53.

12. American Joint Committee on Cancer. AJCC Cancer staging manual. $6^{\text {th }}$ Chicago, III; 2002.

13. Sauer R, Becker $H$, Hohenberger W, Rödel C, Wittekind $C$, Fietkau $R$, et al. Preoperative versus 
postoperative chemoradiotherapy for rectal cancer. N Engl J Med. 2004;351(17):1731-40.

14. Martin LK, Bekaii-Saab T. Optimizing neoadjuvant therapy for rectal cancer with oxaliplatin. J Natl Compr Canc Netw. 2013;11(3):298-307.

15. Brown G, Radcliffe AG, Newcombe RG, Dallimore NS, Bourne MW, Williams GT. Preoperative assessment of prognostic factors in rectal cancer using high-resolution magnetic resonance imaging. Br J Surg. 2003;90(3):355-64.

16. Trakarnsanga A, Gonen M, Shia J, Goodman KA, Nash GM, Temple LK, et al. What is the significance of the circumferential margin in locally advanced rectal cancer after neoadjuvant chemoradiotherapy? Ann Surg Oncol. 2013;20(4):1179-84.

17. Mortensen LA, Leffers AM, Holck S, Bülow S, Achiam $M$. Magnetic resonance imaging in the preoperative staging of rectum cancer. Ugeskr Laeger. 2009;171(35):2476-81.

18. Brown G, Richards CJ, Bourne MW, Newcombe RG, Radcliffe AG, Dallimore NS, et al. Morphologic predictors of lymph node status in rectal cancer with use of high-spatial-resolution MR imaging with histopathologic comparison. Radiology. 2003;227(2):371-7.

19. Kim JH, Beets GL, Kim MJ, Kessels AG, BeetsTan RG. High-resolution MR imaging for nodal staging in rectal cancer: are there any criteria in addition to the size? Eur J Radiol. 2004;52(1):78-83.

20. Hopkins S, Fakih M, Yang GY. Positron emission tomography as predictor of rectal cancer response during or following neoadjuvant chemoradiation. World J Gastrointest Oncol. 2010;2(5):213-7.

21. Chang GJ, You YN, Park IJ, Kaur H, Hu CY, Rodriguez-Bigas MA, et al. Pretreatment high-resolution rectal MRI and treatment response to neoadjuvant chemoradiation. Dis Colon Rectum. 2012;55(4):371-7.

22. Tulchinsky $H$, Shmueli $E$, Figer $A$, Klausner JM, Rabau M. An interval >7 weeks between neoadjuvant therapy and surgery improves pathologic complete response and disease-free survival in patients with locally advanced rectal cancer. Ann Surg Oncol. 2008;15(10):2661-7.
23. Rödel C, Liersch T, Becker H, Fietkau R, Hohenberger $W$, Hothorn $T$, et al. Preoperative chemoradiotherapy and postoperative chemotherapy with fluorouracil and oxaliplatin versus fluorouracil alone in locally advanced rectal cancer: initial results of the German CAO/ARO/ AIO-04 randomised phase 3 trial. Lancet Oncol. 2012;13(7):679-87.

24. Kuriu Y, Kokuba Y, Murayama Y, Komatsu S, Shiozaki A, Ikoma $\mathrm{H}$, et al. Neoadjuvant chemoradiotherapy for locally advanced rectal cancer. Gan To Kagaku Ryoho. 2012;39(12):1951-3.

25. Harb-Gama A, Perez RO, Julião GPS. Terapia neoadjuvante e adjuvante no câncer de reto. Conduta na resposta completa. In: Campos FGCM, Regadas FSP, Pinho M, editores. Tratado de Coloproctologia. São Paulo: Atheneu; 2012. cap.30.2, p.455-62.

26. Hiotis SP, Weber SM, Cohen AM, Minsky BD, Paty PB, Guillem JG, et al. Assessing the predictive value of clinical complete response to neoadjuvant therapy for rectal cancer: an analysis of 488 patients. J Am Coll Surg. 2002;194(2):131-5; discussion 135-6.

27. Habr-Gama A, Perez RO, Nadalin W, Sabbaga J, Ribeiro U Jr, Silva e Sousa AH Jr, et al. Operative versus nonoperative treatment for stage 0 distal rectal cancer following chemoradiation therapy: long-term results. Ann Surg. 2004;240(4):711-7; discussion 717-8.

28. Habr-Gama A, Perez RO, Kiss DR, Rawet V, Scanavini A, Santinho PM, et al. Preoperative chemoradiation therapy for low rectal cancer. Impact on downstaging and sphincter-saving operations. Hepatogastroenterology. 2004;51(60):1703-7.

Received: 01/1022015

Accepted for publication: 08/03/2016

Conflict of interest: none.

Source of funding: none.

Mailing address:

Karina Dagre Magri

E-mail: karinamagri@gmail.com 